\title{
A unidade deslizante da obra Photomaton \& Vox, de Herberto Helder
}

\author{
A sliding unit of work Photomaton \& Vox, by Herberto Helder \\ ROBERTO BEZERRA de MENEZES* \\ Universidade Federal de Minas Gerais, Belo Horizonte, MG, Brasil
}

\begin{abstract}
Resumo: O presente artigo aproveita a noção de unidade da obra para pensar a produção de Herberto Helder, em especial Photomaton \& Vox, livro híbrido feito da experimentação de diversos gêneros. Importa-nos, portanto, pensar em que medida alguns textos do conjunto nos ajudam a entender as ideias de fragmentação, unidade, totalidade e continuidade para o caso em questão, partindo do conceito de álbum para Roland Barthes.
\end{abstract}

Palavras-chave: unidade; obra; Herberto Helder.

\begin{abstract}
The present article takes advantage of the notion of unity of the work to think about the production of Herberto Helder, in particular Photomaton \& Vox, hybrid book made from the experimentation of several genres. It is important, therefore, to think to what extent some texts from the set help us to understand the ideas of fragmentation, unity, wholeness and continuity for the case in question, starting with the concept of album from Roland Barthes.
\end{abstract}

Keywords: unity; work; Herberto Helder.

O presente artigo tem como horizonte de reflexão a ideia de unidade da obra, conceito que, aqui, é colocado em tensão com a obra Photomaton \& Vox, de Herberto Helder, exemplo de hibridismo de gêneros: o relato autobiográfico e o recurso ao diário, a narrativa curta, o poema, o texto crítico, o ensaio experimental, o comentário, o aforismo, textos dispersos de catálogos de arte convivem sob o mesmo título, fazendo instáveis as lindes do texto literário e do texto crítico, ou, para recuperar o comentário de Gustavo Ribeiro: “[...] o livro parece desafiar qualquer classificação, não se deixando capturar pelo discurso crítico que quer aprisioná-lo em categorias e conceitos estanques" (2009, p.177). Essa instabilidade não permite ao leitor inferir uma ordem, uma unidade, não há possibilidade de leitura orientada pela existência de um sumário, por exemplo. Cabe, portanto, ao leitor, fazer uso do livro seguindo a ordem das páginas, tendo em vista o imperativo da dobra no imaginário

\footnotetext{
* Doutorando em Estudos Literários na Universidade Federal de Minas Gerais (UFMG). <robertobmenezes@gmail.com>
} 
do livro (MELOT, 2012) ou, ainda, em modo aleatório, pois, como é preciso deixar claro, não existe uma progressão temática ou reflexiva que justifique a necessidade de ordem para a leitura dos textos de Herberto Helder ali agrupados. Nosso procedimento de reflexão passa pelo tensionamento das ideias de Roland Barthes, em especial a ideia de álbum, e de uma demonstração das possiblidades textuais presentes em Photomaton \& Vox.

O caráter fragmentário de Photomaton \& Vox não é exclusivo na produção do poeta português Herberto Helder. Sua obra poética, de acordo com o autor, é fruto de um processo contínuo que buscou reunir folhetos publicados ao longo dos anos. A afirmativa do poeta, em sua famosa autoentrevista, publicada primeiramente na revista Luzes de Galiza e aqui no Brasil na revista Inimigo Rumor, na qual diz ser um "autor de folhetos" (2001, p. 190) e que escreveu "apenas um poema, um poema em poemas" (2001, p.192), é um dos pontos de partida para se pensar o seu projeto literário.

Outro ponto interessante a se ressaltar é que, para Helder, a autoria passa pela operação de montagem, de combinatória de imagens tecidas na memória (2006, p.138-143, texto que constava em Cobra, obra esfacelada e em parte destruída). Esse fluxo de imagens é articulado de modo a formar uma sintaxe toda feita de imagens. Ora, se pensarmos essas duas ideias em conjunto, veremos que a obra contínua de Helder, não somente no nível de seus folhetos, é também parte dessa articulação entre memória e montagem.

A este ponto talvez seja importante acrescentar os projetos de recolhas empreendidos por Helder ao longo dos seus 84 anos de vida: Ofício cantante (1967),
Poesia toda (1973 e emendada nos anos de 1981, 1990 e 1996), Herberto Helder ou o poema contínuo: súmula (2001), Ou o poema contínuo (2004), A faca não corta o fogo: inédito e súmula (2008), Ofício cantante - poesia completa (2009) e Poemas completos (2014). Ao longo de todas essas reordenações em suas recolhas, com revisões, reescritas, decréscimos e acréscimos, o poeta acaba por fazer colidir todos os planos de montagem feitos. O espaço da obra, então, é visto em expansão e retração, em movimento, portanto. Mas esse espaço só pode ser visto na relação com o tempo, com alternações entre sincronia e diacronia, a depender do propósito do leitor. Como disse Helder no texto "(memória, montagem)": "tudo isto reproduz a relação pessoal com o espaço e o tempo, quero eu dizer: uma montagem, uma noção narrativa própria" (2006, p. 139). Ou ainda: "Não existe outra metáfora que não seja o espaço; aquilo a que chamam metáforas são linhas de montagem narrativa, o decurso da alegoria, o espetáculo." (2006, p. 140).

A estratégia da recolha e da reescrita é, portanto, um movimento obsessivo do poeta em refazer esse todo, sempre pronto a ruir, com a aparição de um novo folheto ou com a decisão do poeta de suprimir, reescrever, acrescentar poemas ao poema contínuo, essa espécie de linha de montagem narrativa, como o disse o poeta. Mesmo a última recolha publicada em vida, Poemas completos, é, hoje, automaticamente incompleta, na medida em que temos, lançado em 2015 e 2016, mais dois livros de Helder: Poemas canhotos, livro póstumo do autor que teria, segundo seu editor na Porto Editora, sido organizado ainda em vida, e Letra aberta, poemas escolhidos pela viúva Olga Lima 
entre os que o poeta deixou manuscritos. Se esses livros póstumos irão ser acrescentados a uma súmula posterior, não se sabe, mas é certo que esse movimento de acréscimo não será mais feito pelo autor ele mesmo, falecido a 23 de março de 2015.

Se o poeta decidiu assim nomear a última súmula que pode fazer em vida, em que consta o seu poema feito de poemas, o poema contínuo agora poemas completos plural, desunidos, finalizados -, essa atitude também mostra o horizonte de totalidade que obcecava o poeta, desejoso de cumprir a servidão, o ofício cantante, para recuperar o título da recolha anterior, a que nunca conseguiu escapar. Essa ideia de totalidade também acompanha o título da primeira recolha: Poesia toda, como acompanharia o projeto de reunião de sua prosa: Prosa toda, o que nunca veio a acontecer. É certo que Helder era um leitor de si mesmo. Para ele, ler era sim refazer esse todo, sem deixar de reconhecer que esse todo era fruto de fragmentos, chamados folhetos, a que o poeta continuamente impôs reordenações e montagens diversas.

A esse pensamento em torno da obra de Herberto Helder talvez seja interessante acrescentar as reflexões de Roland Barthes sobre A preparação do romance. Em sua primeira prova: a escolha, a dúvida, Barthes fala dessa atitude do escritor perante a escolha de uma imagem-guia a seguir, uma fantasmática forma no horizonte do desejo. Ainda que não seja aqui o caso da escrituração de um romance, as atitudes de escolha e dúvida são sentidas no projeto de Helder. Nessa primeira prova também é importante a distinção empreendida por Barthes ${ }^{1}$ entre as formas fantasiadas livro e álbum, que podem nos por a pensar tanto

\footnotetext{
1 A distinção vem de Mallarmé, que praticava o álbum e o condenava, segundo Barthes.
}

o poema contínuo helderiano quanto Photomaton \& Vox, a que retornaremos mais à frente. Até que ponto as sucessivas recolhas podem se configurar como uma tentativa de desestabilizar o mito coletivo do livro, segundo os preceitos de unidade e coerência? Se o livro é arquitetural e premeditado, as súmulas de Helder também o são, ainda que nelas, uma após outra, haja essa rasura do trabalho feito e a sua substituição para efeito de atualidade do projeto do autor?

Sem nos ater ao objetivo de encontrar respostas para as perguntas que habitam a primeira parte desse texto, procuraremos, mais objetivamente, retornar à discussão envolvendo o caso Photomaton \& Vox, agora o relacionando à ideia de álbum, como propôs Barthes. Para isso, optamos por apresentar algumas ideias presentes em textos diversos do volume, o que ajuda a entender não só as ideias de Helder a propósito do que seja a escrita literária, mas dá a ver a multiplicidade de tipos discursivos ali reunidos.

Photomaton \& Vox, livro de Helder que apresenta cinco edições (1979, 1987, 1995, 2006 e 2015), com emendas a cada edição, e que traz em seu seio um grande número de gêneros dispares, pode ser associado à ideia de álbum, mas, por força da contingência, hoje é visto como livro em sua unidade fragmentária.

Se está em questão falar de unidade, podemos partir de algumas linhas de força que estão presentes em diversos textos de Photomaton \& Vox que dão ideias sobre o que é a escrita para o autor. "- Esta / espécie de crime que é escrever uma frase que seja" (2006, p. 8) é o que desencadeia a desordem que preside a montagem do texto literário de Helder: "A minha força é a desordem" (2006, p. 8). 
Entretanto, essa espécie de crime presidido por uma aparente desordem dá também espaço para os traços autobiográficos, já apontados por Gustavo Silveira Ribeiro (2009). Silveira toma as ideias de Deleuze, em "A literatura e a vida", para apontar em Photomaton \& Vox a noção de vida escrita, fundada em "neutralidade", "corporeidade e o permanente estado de metamorfose" (RIBEIRO, 2009, p. 181). É o que se percebe, por exemplo, no texto intitulado "(photomaton)", o primeiro em prosa, o segundo após o poema de abertura, e que dá em parte nome ao volume:

Mas vivi em África, longe de toda a cartografia vertente, longe também da intenção mitográfica euro-africana - e aconteceram-me alguns entremezes sinistros e iluminantes. Vi leprosos, fui tocado por leprosos. Vi a guerra, a morte frontal, a minha morte - e vi os desertos. Vi-me a mim próprio subindo, numa metamorfose exasperada, dos precipícios do pavor até às estritas regras da vida. E estava maduro para ver tudo. Desejei então ser eu mesmo o mais obscuro dos enigmas vivos, e aplicar as mãos na matéria primária da terra. Gostaria de ser um entrançador de tabaco (2006, p. 12).

A partir desse trecho, percebemos que a "matéria primária da terra" é não só relacionável ao mais iminente discurso autobiográfico, mas é também elemento do mundo ali encenado, reaproveitado, deglutido em ação antropofágica. Essa atitude de alimentação nas culturas não eurocêntricas confere a Helder um notável lugar em Portugal, ainda afeito às questões locais e circundantes. A atitude de proximidade ao "aplicar as mãos" demonstra bem o ideal helderiano de metamorfose do sujeito com as matérias do mundo, desencadeado a experiência literária.

No fragmento "(carta do silêncio)", Herberto Helder coloca em cena preocupações com a linguagem da experiência literária de modo mais explícito. O poeta português admite pensar que a poesia vem do silêncio, atravessa-o e nele se multiplica, em direção ao fim mesmo que, sendo um por vir, só se pode supor tratar da mesma matéria: silêncio, pois "tudo acaba onde começa" (2006, p. 164). Por outro lado, o silêncio, neste trecho, é também da ordem do silêncio do corpo, como uma recusa eventual que acomete os escritores. Hölderlin, Nietzsche, Rimbaud, Trakl, Sá-Carneiro, Crane, Plath, Celan e Lorde Chandos são evocados pelas posições de recusa, seja de isolamento seja de suicídio, um silêncio mais radical. A importância de Rimbaud para a experiência moderna, para Helder, se deve a ele acreditar que "o silêncio é que deveria ter sido o ponto de partida para a experiência espiritual da modernidade" (HELDER, 2006, p. 126).

De modo irônico, mas didático, Helder (2006, p.126) procura relacionar a experiência literária com o silencio quando diz haver apenas duas possiblidades para a escrita, apresentar ou representar:

Levar a linguagem à carnificina, liquidar-lhe as referências à realidade, acabar com ela - e repor então o silêncio.

Fingir escolarmente que não aconteceu nada - e escrever poemas cheios de honestidades várias e pequenas digitações gramaticais, com piscadelas de olho ao "real quotidiano". Aqui, o autor diz: desculpa, sr. dr., mas: merda! Em outro fragmento, "(em volta de)", Helder começa evocando um discurso em primeira pessoa, aproximando-nos desse enunciador como se estivéssemos 
a ter com o próprio autor que assina a capa. Nesse início, temos a impressão que se trata de uma narrativa com veleidades autobiográficas. $\mathrm{O}$ que, veremos, o próprio texto irá refutar. O enunciador, então, diz: "Vou dizer como foi: aluguei uma casa. Só tinha uma cama para pôr lá dentro, mais nada. Bom. Alguns livros e um giradiscos. Sim." (2006, p.64).

Ora, parece-nos que ali estamos a escutar o narrar de um fato cotidiano, ordinário. Porém, veremos que, em um afirmar e refutar de ideias, a linguagem de Herberto Helder sempre comportará em seu seio o simbólico como desmedida.

Como de certo, o fato é apenas desculpa para o enunciador começar a escrever. E ele escreve exatamente o que estava acontecendo, como se fosse um diário do presente tornando-se passado, um tempo tornado objeto a perder-se de sua origem, em um repetir de movimentos e inércias, ações e pensamentos deste ser: "Comecei então a escrever aquilo mesmo." (2006, p.64-65). E na tentativa de escrever o presente, viu-se tomado pelo passado, pois "A escrita foi-me conduzindo a outro tempo, um tempo simétrico." (2006, p. 65). Não fica evidente, pelo termo utilizado, se se trata de fato do passado, mas, como podemos pensar, o "tempo simétrico" e o que logo após ele chama de "matéria cristalográfica do tempo" são uma possível referência a um tempo regular, sem a instabilidade que parece saltar do discurso que enuncia um presente na narrativa, como um cristal que conserva certa transparência, mas com resvalar difusos de energias e imagens. O passado, nesse sentido, não seria uma correspondência com o presente nem com os fatos do passado em si, mas uma nova instância edificada pela imperfeição do retorno feito no presente, também instável e maleável. Vale lembrar, aqui, do procedimento de memória e montagem que Helder admite fazer uso.

Na infância havia uma casa onde eu andara assim, por corredores e quartos. Como direi? Escrevendo, descobrira que cada facto ocorrido hoje correspondia a outro ocorrido na infância. Mas isto era outra coisa. Verifiquei por exemplo que, ao escrever sobre o passado, eu o atraiçoava, revelando-o apenas como visão presente. Assim, a experiência é mantida como hipótese de investigação que acolhe sempre a dúvida, ou dela se alimenta. (2006, p.65)

A infância que Herberto Helder intentaria recordar através do contato com a casa vazia, com paredes silenciosas, é a experiência que comporta em si a dúvida, refutando a possibilidade da verdade certa, pois "a memória tem a sua parte de esquecimento" (2006, p.34), é "improvável" (2006, p.66). Os fatos do hoje corresponderiam a fatos da infância, numa repetição circular, mas, logo a frente declara: "As relações entre as diversas partes desta realidade descontínua são esquivas, móveis, ambíguas." (2006, p. 65). Recorre, então, "à parábola, à alegoria, à metáfora" (2006, p.65), tornando-se pelo que nunca poderá ser, ou seja, instaurando-se enquanto discurso mais próximo do teor literário e artístico que científico, ser constituído de fluídos oblíquos.

A "escrita circular" não remete somente a um retorno ao ponto de partida, como se pode pensar em princípio. A maior implicação, de acordo com Helder, resulta na insolubilidade, "porque nenhuma solução é possível, por nunca se poder provar a hipótese de verdade da coisa escrita" (2006, p.65). Temos, então, uma escrita que se desdobra sobre si mesma, 
em movimentos de experimentação, um fazer no ser e um ser no fazer, texto fechado e, ao mesmo tempo, aberto. Helder nos explica: "Fechado sobre si", um retorno ao mesmo com possibilidades outras, e aberto "porque as possibilidades dessa consideração se mostravam praticamente sem número" (2006, p. 65-66).

No fragmento "(nota para não escrever)", Helder articula elementos dos textos anteriormente citados, como o silêncio, a solidão, o esquecimento do mundo e a morte como elementos que, na escrita, tem conexão com a energia espiritual e com a metamorfose interior:

Se o conhecimento é uma forma de escrita, mesmo sem palavras, uma respiração calada, a narrativa que o silêncio faz de si mesmo, então não se deve escrever, nem mesmo admitindo que fazê-lo seria o reconhecimento do conhecimento. Pode escrever-se acerca do silêncio, porque é um modo de alcança-lo, embora impertinente. Pode também escrever-se por asfixia, porque essa não é maneira de morrer. Pode ainda escrever-se por ilusão criminal: às vezes imagina-se que uma palavra conseguirá atingir mortalmente o mundo. A alegria de um assassinato enorme é legítima, se embebeda o espírito libertando-o da melancolia da fraternidade universal. Mas se apesar de tudo se escrever, escreva-se então para estar só. A escrita afasta concretamente o mundo. Não é o melhor método, mas é um (2006, p. 78).

Por outro lado, há em Photomaton \& Vox textos que, se não fogem a esse caráter ensaístico e metaliterário, são frutos de práticas outras, como o texto de catálogo: "(este escrito pode ser utilizado como ironia ao modelo crítico vigente / o modelo possui meia dúzia de variantes / pretexto: uma exposição de escultura)" (2006, p.69-74). É o tipo de texto helderiano que faz uso de um tipo discursivo já posto em ata, mas que reordena, por meio da ironia, o seu uso e o seu propósito primeiro: serve de entrada para a exposição, mas também serve de barreira para ela. Ou ainda o "(actionwriting)" (2006, p.80-82), em que se tem um conteúdo reflexivo a pensar a própria escrita que se escreve na leitura, como a substituir um poema possível, mas articulado em cortes próximos aos cortes poemáticos: um poema e um não-poema, uma forma e um conteúdo em desarrumação:

Desejaria que este escrito fosse um puro teorema poético de violência, e as suas personagens:

a) a minha mão estendida como uma arma viva;

b) as vozes;

c) certos silêncios;

d) luzes;

- ou então:

a) a noite que entra na claridade, ou o dia como um movimento ríspido, uma precipitação no meio do escuro;

b) a enxuta matéria do mundo;

c) o corpo luzente;

d) sangue a escorrer por toda a parte: na leveza, na força, no sono - a repentina beleza do sangue em volta da raiz, o seu poder (2006, p. 80-81).

Outro momento de estranhamento em Photomaton \& Vox é o texto "(o humor em quotidiano negro)". Nesse texto, Helder faz uso de episódios rápidos e irônicos, com referências ao humor negro e ao cotidiano em parte ordinário, em parte inusitado. Alguns exemplos: "Foi posto à venda o primeiro número de uma revista de cultura e intervenção cujas folhas, tratadas com uma substância química especial, se inflamam e consomem em contacto com o ar." (2006, p. 86). E mais: "Um jovem espancou um tubarão dando-lhe pontapés na boca. Apesar de muito maltratado, o tubarão conseguiu escapar." (2006, p.89). 
E ainda: "Um homem de 30 anos encontrase em estado de coma, após haver tentado suicidar-se comendo um sanduíche de pão com lâminas de barbear." (2006, p. 90). Várias são as situações de autoflagelação e de morte, como em:

Um indivíduo andava com uma pequena ferida no polegar da mão esquerda. Dizia que aquilo o maçava. Hoje, entrou numa taberna, pediu uma faca bem afiada e, com dois golpes certeiros, cortou o dedo. Depois, com a maior naturalidade, pegou no polegar sangrento, aproximou-se da porta e deitou-o fora (2006, p. 91).

Em "(carta a uma instituição requerendo uma bolsa)" (2006, p. 103-108), Helder faz uso do gênero epistolar para, em atitude negativada, requerer uma bolsa não pelo mérito acadêmico, mas pela inadequação à institucionalização de seu discurso. Critica a Academia e se coloca como louco:

Enquanto nós, os loucos, nos alimentamos de apenas intransigência, emoções truculentas, cândida violência de ideias, e vivemos da luminosidade da própria cabeça, os senhores, tão irrefutavelmente sentados à mesa antropófaga, devoram o, por assim dizer, nosso corpo literal. (2006, p. 105).

Eis, pois, alguns exemplos de textos que compõem não somente o volume, mas que denunciam a história constitutiva de Photomaton \& Vox, que aponta para o caráter circunstancial em que a obra foi concebida e reconcebida. Ainda que reunidos sob o mesmo título, os textos ali presentes são pequenas mônodas que funcionaram desarticuladas do todo que é o livro, ainda que se liguem pelo discurso autoremissivo de caráter metatextual, com intensidades diferentes a depender do texto em causa.
São diversos os exemplos de fragmentos que fazem direta menção a livros de Helder, o que nos lembra do projeto de Livro de Mallarmé, do qual "resta um manuscrito de 200 folhas, que não são o Livro, mas pensamentos sobre o Livro" (BARTHES, 2005, p. 117). Assim, ainda que dispersos e passíveis de descolamento do todo, esses textos orbitam no cosmoshelder, cabendo ao leitor perceber os feixes de energia que interligam todos esses discursos produzidos pelo poeta português. Costurar, montar: operações também de leitura, não exclusivas da escrita. Helder costurou a dobra do livro, mas resta ao leitor costurar os textos, para além da relação no dado livro, em conjunto com o todo mais amplo, disperso. Assim, podemos inferir que Photomaton \& Vox só apresenta traços de totalidade pelo gesto extratextual, do alinhamento dos textos sob o mesmo título, da costura da dobra, do gesto do autor de montagem.

Se "o livro é um mito coletivo" (BARTHES, 2005, p.115), como apontou Barthes, é preciso ressaltar que a noção de álbum não é tão transparente no seio da sociedade. De acordo com Barthes, o álbum não deveria ser visto como algo menor, mas parte de uma visão inessencial de mundo, bem condizente com o estatuto dito pós-moderno. A obra como objeto, uma totalidade material (BARTHES, 2005, p.105) não é aqui questão, visto que esse ponto depende mais da costura e da dobra, atitudes feitas pelo poeta, mas que não se sustentam como único argumento.

Talvez seja necessário aqui expor os critérios de Barthes, a partir de Mallarmé, para a delimitação mínima do que seja o álbum. Dois são os critérios que fazem o álbum: o circunstancial e o rapsódico. Circunstancial porque percebe-se uma "ausência de estrutura: conjunto factício 
de elementos cuja ordem, a presença ou a ausência são arbitrárias $\rightarrow$ Uma folha de álbum se desloca ou se acrescenta segundo o acaso; procedimento absolutamente contrário ao do Livro" (BARTHES, 2005, p. 123); rapsódico porque é a "Ideia do Costurado, Montado, Patch-Work" (BARTHES, 2005, p. 124).

Diante disso, podemos nos colocar novas questões: Photomaton \& Vox é um álbum somente se o leitor tiver consciência de sua ausência de eixo estrutural? Em sua quarta e última edição, com a ordem de fato posta e imutável pelo autor, pode ser considerado livro apenas pela sua dada estrutura física e material, pela ausência de possibilidade vindoura da mão do autor a embaralhar os textos? O que há internamente que pode boicotar essa ideia de livro enquanto unidade discursiva progressiva? Se para a condição de livro é necessário haver certa cadência, como recupera Barthes a partir da distinção da música de Schöenberg e Cage, então Photomaton \& Vox, pela sua atonalidade, pela falta de cadência e de centro, pode ser considerado um álbum, ainda que transformado em livro físico pelas circunstâncias.

Ao autor coube escolher não somente as formas livro ou álbum, mas também abraçar as implicações que tais escolhas contém. Perguntamo-nos, então, se Herberto Helder escolheu uma forma ou outra, visto que ao longo de nossa discussão apontamos haver um descompasso entre a dobra que o torna livro e a ausência de centro e de progressão que o aproxima do álbum. Ainda que se considere a condição de livro de Photomaton \& Vox, é preciso talvez entender sobre o viés de Cage, citado por Barthes, que a dispersão tem sua parte de glória e que o livro tende a se movimentar para a desorganização, sendo o rapsódico parte desse "apelo de uma verdade no mundo" (BARTHES, 2005, p. 131).

Se o livro é também entendido como "homólogo ao mundo" (BARTHES, 2005, p.130), então o poema contínuo de Helder, em sua ambição de totalidade, pode ser entendido como essa busca de parelhamento ao mundo, algo que, como vimos, não se faz notório em Photomaton \& Vox. Mas se, como o disse Barthes, o Livro volta a ser Álbum, se a ruína é o futuro do monumento, o Álbum é o futuro do Livro; se o que resta do Livro é a citação, o fragmento e o leitor despedaça o Livro, então pode-se dizer que Helder joga com o leitor na medida em que experimenta a tensão entre fragmento e totalidade em suas obras. Assim, nos competiu pensar esses movimentos empreendidos ao longo de sua produção poética e fazer notar essas tensões que parecem ter muito mais contribuído que prejudicado a imagem que se tem do poeta e de sua obra, hoje, em Portugal e em parte do mundo.

\section{Referências}

BARTHES, Roland. A preparação do romance. Tradução de Leyla Perrone-Moisés. São Paulo: Martins Fontes, 2005. Vol. 2: A obra como vontade.

HELDER, Herberto. Photomaton \& Vox. 4.ed. Lisboa: Assírio \& Alvim, 2006.

. "Entrevista". In: Inimigo Rumor, n. 11. Rio de Janeiro: 7 letras, 2o semestre de 2001.

MELOT, Michel. Livro. Tradução de Marisa Midori Deaecto e Valéria Guimarães. Cotia: Ateliê Editorial, 2012.

RIBEIRO, Gustavo Silveira. "Os paradoxos da escrita autobiográfica em Photomaton \& Vox de Herberto Helder". Revista Interdisciplinar, ano IV, v. 8, p.177-182, 2009. Disponível em: <http:// www.seer.ufs.br/index.php/interdisciplinar/article/ view/1196/1034>.

Recebido: 9 de maio de 2017.

Aceite: 15 de novembro de 2017. 